removed, principally in the form of long hospital waiting times and the costs of visiting hospital, both identified as inconvenient by patients in a previous study. ${ }^{4}$ Patients' perceptions and attitudes may have changed; they may feel more willing to pursue treatment having consulted their general practitioner, or, having become aware of the possibility that he or she could treat them, may have been more likely to seek help in the first instance. Greater public awareness of the dangers of skin cancer may also contribute.

The 1990 contract effectively gave priority to funding minor surgery by general practitioners up to a theoretical maximum of $£ 31 \mathrm{~m}$ per year in England, approximately $2 \%$ of the general medical services budget. The sum spent in 1991 was estimated as $£ 23 \mathrm{~m} .{ }^{14}$ The consequent expansion of minor surgery in general practice has not been simply a transfer to a more cost effective setting. This result brings into question whether a further expansion would, as has been suggested, ${ }^{14}$ necessarily transfer activity from hospital to the community to any great extent. It also raises the question of whether the health benefits from minor surgical activity by general practitioners justify the priority funding.

This study was commissioned by the Department of Health, which, along with Trent Regional Health Authority, funds the core staff of the Medical Care Research Unit. We thank Ms Juliet Brown, Dr Tim Usherwood, and the general practitioners and hospital doctors who participated in the study. (C) Crown copyright 1993.

1 Brown JS. Minor operations in general practice. $B M F$ 1979;i:1609-10.

2 Coopers and Lybrand Associates. The cost-effectiveness of general practice; a General Medical Services Committee discussion document. London: British Medical Association, 1983.

3 Coid DR. General practitioner minor surgery facilitated by a Fife district general hospital. Health Bulletin 1990;48(3);132-6.

4 O'Cathain A, Brazier JE, Milner PC, Fall M. The cost-effectiveness of minor surgery in general practice; a prospective comparison with hospital practice. surgery in general practice; a
$B r$ G Gen Pract 1992;42:13-7.

5 Fry J. General practice surgery-a national need? Update 1984;29:293.

$6 \mathrm{Hunt} \mathrm{JH}$. The scope and development of general practice in relation to other branches of medicine. A constructive review. Lancet 1955;ii:681-7.

7 British Medical Association. General Medical Services Committee-report of the New Chaner Working Group. London: BMA, 1979.

8 Department of Health and Social Security. Promoting better health; the government's programme for improving primary health care. London: $\mathrm{HMSO}$ 1987. (Cm 249.)

9 Department of Health, Scottish Home and Health Department, Welsh Office General practice in the National Health Service. The 1990 contract. The government's programme for changes to general practitioners' terms of service and government's programme for changes to general prc

10 Hanley JA, Lipmann-Hand A. If nothing goes wrong, is everything all right? Interpreting zero numerators. $¥ A M A$ 1983;249:1743-5.

11 Dean AD, Dean JA, Burton JH, Dicker RC. Epi-info version 5: a word processing, database and statistics program for epidemiology on microcomputers. processing, database and statistics program for

12 Shrank A. Counting the cost of eager GPs' minor ops. Hospital Doctor 1992 May 21;C12:26.

13 McWilliam LJ, Knox F, Wilkinson N, Oogarah P. Performance of skin biopsies by general practitioners. $B M \mathcal{F} 1991 ; 303: 1177-9$.

14 Boyle S, Smaje C. Minor surgery in general practice: the effect of the 1990 GP contract. In: Harrison A, ed. Health care UK 1991. London: King's Fund Institute, 1992.

(Accepted 26 May 1993)

\title{
Cryptosporidiosis in infancy and childhood mortality in Guinea Bissau, West Africa
}

\author{
Kåre Mølbak, Niels Højlyng, Adam Gottschau, José Carlos Correia Sá, Liselotte Ingholt, \\ Augusto Paulo José da Silva, Peter Aaby
}

Laboratory of Parasitology, Statens Seruminstitut, Copenhagen, Denmark

Kåre Mølbak, research fellow Niels Højlyng, research fellow

Liselotte Ingholt, public health nurse

Department of Statistics, Statens Seruminsititut, Copenhagen, Denmark Adam Gottschau, statistician

National Public Health Laboratory, Bissau, Guinea Bissau

José Carlos Correia Sá, technician

Augusto Paulo José da Silva, coordinator

Epidemiology Research Unit, Statens

Seruminstitut,

Copenhagen, Denmark

Peter Aaby, senior researche

Correspondence to:

Dr K Mølbak,

Epidemiology Research

Unit, Statens Seruminstitut,

Artillerivej 5, DK-2300,

Copenhagen S, Denmark.

BMF 1993;307:417-20

\section{Abstract}

Objective-To investigate the epidemiology of and mortality from cryptosporidiosis in young children in Guinea Bissau, West Africa.

Design-Three year community study of an open cohort followed up weekly.

Setting-301 randomly selected houses in a semiurban area in the capital, Bissau.

Subjects-1315 children aged less than 4 years.

Main outcome measures-Cryptosporidium infection detected by examination of stools during episode of diarrhoea and death of a child.

Results-Cryptosporidium spp were found in 239 $(7 \cdot 4 \%)$ out of 3215 episodes of diarrhoea. The parasite was most common in younger children (median age 12 months) and at the beginning of the rainy seasons. The prevalence of cryptosporidiosis was $15 \%(77 / 513)$ in cases of persistent diarrhoea compared with $6 \cdot 1 \%(148 / 2428)$ in diarrhoea lasting less than two weeks $(p<0 \cdot 0001)$. Cryptosporidiosis was associated with excess mortality in children who had the infection in infancy, and this excess mortality persisted into the second year of life (relative mortality $2.9(95 \%$ confidence interval 1.7 to 4.9)). The excess mortality could not be explained by malnutrition, or by socioeconomic factors, hygienic conditions, or breast feeding.

Conclusions-Cryptosporidiosis is an important cause of death in otherwise healthy children in developing countries.

\section{Introduction}

The protozoan Cryptosporidium paroum has emerged during the past decade as a cause of severe diarrhoea in immunodeficient patients. Cryptosporidiosis is also recognised as a cause of diarrhoea in otherwise healthy people but the infection is thought to be self limiting. ${ }^{1}$ However, associations have been reported between cryptosporidiosis and failure to thrive or malnutrition, persistent diarrhoea, ${ }^{23}$ and impaired delayed skin hypersensitivity ${ }^{4}$ in immunocompetent patients, particularly children in developing countries. We conducted a community study to investigate the epidemiology of cryptosporidiosis in a cohort of young children in Guinea Bissau, West Africa.

\section{Subjects and methods}

The study was conducted as part of a three year prospective community based surveillance of diarrhoea among children aged below 4 years from a semiurban district, Bandim II, in the capital of Guinea Bissau. ${ }^{5}$ In brief, all children born after 1 June 1984 residing in a random sample of 301 houses were included in the study, which started on 1 April 1987. Children born in or moving to these houses were also included. Children who moved within the area were followed up from their new houses. Follow up of children born during June 1984 to May 1985 was stopped in April 1988 and of children born during June 1985 to May 1986 in April 1989. A total of 471 children were included when the study started, and the study comprised 1315 children by the end (31 March 1990).

The children were followed up weekly by field workers, who collected information on episodes of diarrhoea during the previous week. If a child had diarrhoea a stool sample was collected later the same day, if possible. A sequence of days with diarrhoea was regarded as one episode of diarrhoea provided that it 
was separated from a previous episode by at least two days. ${ }^{2}$ Detailed information on possible confounding socioeconomic background factors was collected in the first year of the study.

\section{MICROBIOLOGICAL METHODS}

Stools were collected in plastic containers and kept in an insulated box with ice packs until processing, which was done within 15-18 hours. About $1 \mathrm{~g}$ of faeces was concentrated by the formol-ether technique, ${ }^{6}$ and a smear was stained by the modified Ziehl-Neelsen technique ${ }^{7}$ and examined microscopically. An episode of diarrhoea was considered to be due to cryptosporidium if the parasite was found in at least one stool sample from the episode.

\section{NUTRTTIONAL STATUS}

All children had their weight measured every three months, by using a portable spring scale. The weights of children before infection with cryptosporidium were compared with those of a similar number of control children matched for sex, age, and year and month of visit. The difference in mean weight and weight for age $z$ scores was evaluated by paired samples $t$ test after the normal distribution assumptions had been tested for

\section{STATISTICAL METHODS}

We used the $\chi^{2}$ test or Mantel-Haenszel technique, as appropriate, to analyse the data. Mortality in children who had cryptosporidiosis was compared with that in children without cryptosporidiosis, stratified for age and age at time of infection. Children were included in the negative control group until their first stool sample positive for cryptosporidium. The relative mortality was estimated by the density ratios (mortality ratios). ${ }^{8}$ Survival curves were calculated by the Kaplan-Meier product limit technique.

The survival data were further analysed with Cox's proportional hazards regression model. Cryptosporidiosis was included as a time dependent covariate with the value 0 before and the value 1 after a child experienced cryptosporidium diarrhoea. Age at time of cryptosporidium diarrhoea, a logarithmic transformation $(\ln (t+1))$ of time since cryptosporidiosis, and sex were simultaneously included in the analysis. Information on other possible confounding determinants was available for 555 children included in the first study year. The possible confounding effect of weaning, socioeconomic factors, and household characteristics were examined in this subsample. Age was the underlying timescale in the models and each child was included in the analysis from their age at entry in the study. The program BMDP 21 (BMDP Statistical Software, Cork, Ireland) was used.

\section{Results}

During the three study years 3707 diarrhoeal stools were collected, of which $260(7 \cdot 0 \%)$ were positive for Cryptosporidium spp. The samples represented a total of 3215 episodes of diarrhoea; cryptosporidium infection was shown in 239 episodes $(7 \cdot 4 \%)$ in 205 children. Accurate information on duration of diarrhoea was available for 2941 episodes. The prevalence of cryptosporidium in episodes of persistent diarrhoea (at least 14 days $^{2}$ ) was $15 \cdot 0 \%(77 / 513)$ compared with $6 \cdot 1 \%$ $(148 / 2428)$ in episodes lasting less than 14 days. The relative risk of cryptosporidium infection for cases of persistent diarrhoea was 2.5 (95\% confidence interval 1.9 to $3.2 ; p<0.0001$, adjusting for age by MantelHaenszel technique). Table I shows that cryptosporidiosis was significantly more prevalent in the youngest age groups ( $p<0.0001, \chi^{2}$ test). The median age at infection was 12 months.
TABLE I-Age specific prevalence of cryptosporidium infection among children with diarrhoea from an open community cohort of 1315 children in Guinea Bissau, West Africa

\begin{tabular}{lcc}
\hline & \multicolumn{2}{c}{ No of episodes of diarrhoea } \\
\cline { 2 - 3 } Age (months) & Examined & $\begin{array}{c}\text { Positive for } \\
\text { cryptosporidium (\%) }\end{array}$ \\
\hline $0-5$ & 376 & $43(11 \cdot 4)$ \\
$6-11$ & 684 & $70(10 \cdot 2)$ \\
$12-17$ & 597 & $51(8 \cdot 5)$ \\
$18-23$ & 529 & $35(6 \cdot 6)$ \\
$24-29$ & 507 & $14(2 \cdot 8)$ \\
$30-35$ & 379 & $19(5 \cdot 0)$ \\
$36-41$ & 124 & $7(5 \cdot 6)$ \\
$42-47$ & 19 & 0 \\
\hline Total & 3215 & $239(7 \cdot 4)$ \\
\hline
\end{tabular}

Figure 1 shows the number of episodes of cryptosporidiosis and monthly rainfall during the three years. The number of episodes was highest in the months before the maximum rainfall during all three years. The prevalence in the rainy seasons (June to November) was $9 \cdot 1 \%(171 / 1878)$ compared with $5 \cdot 1 \%$ $(68 / 1337)$ in the dry seasons (relative risk $1.8,1.4$ to $2 \cdot 4 ; \mathrm{p}<0.001)$. Mortality was not significantly higher in the rainy season than in the dry season in children without cryptosporidiosis (relative mortality ratio $1 \cdot 4$ $\mathrm{p}=0.54)$ and those with cryptosporidiosis (1.3, $\mathrm{p}=0 \cdot 60$ ).

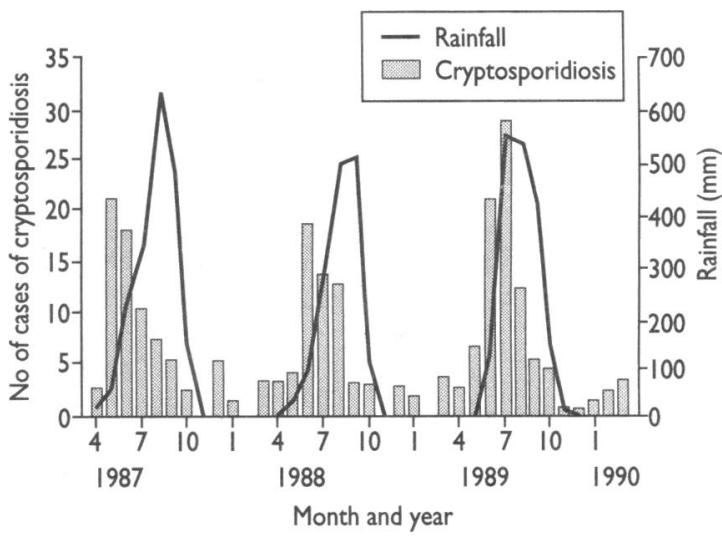

FIG 1-Monthly rainfall (Institute of Meterology, Bissau) and number of episodes of cryptosporidium diarrhoea among 3215 episodes of diarrhoea in children in Bissau, Guinea Bissau, West Africa

\section{MORTALITY}

Of the 205 children in whom cryptosporidiosis was shown, six died within one month after the last positive stool sample. The case death rate (number of episodes as the denominator) was $2.5 \%(6 / 239 ; 95 \%$ confidence interval $0.9 \%$ to $4 \cdot 8 \%), 3.5 \%(4 / 113 ; 1.0 \%$ to $7 \cdot 6 \%)$ in the children less than 1 year and $2 \cdot 3 \%(2 / 86 ; 0.3 \%$ to $6.3 \%$ ) in 1 year old children. No deaths were recorded in 40 episodes among children above 2 years of age.

The 1315 children were followed up for 1640 child years, during which time 88 postneonatal deaths (all causes) were recorded. Twenty two of these were among the 205 children who acquired cryptosporidiosis. Ten of the 22 children died of persistent diarrhoea, two of acute diarrhoea, three of lower respiratory tract infection, three of malaria, and the remaining four of other causes.

The relative mortality for children with cryptosporidiosis was 2.8 in the first year of life $(1.2$ to 6.5 , $\mathrm{p}=0.018)$ and $3.6(1.9$ to $6.9, \mathrm{p}=0.0001)$ in the second year. By excluding children who died within one month of the last positive stool and corresponding time of follow up, the risk of death decreased to $1 \cdot 1(0.3$ to $4 \cdot 3$ ) in infancy but was still significantly higher, $3 \cdot 3$ $(1.6$ to $6 \cdot 6, p=0.001)$ in the second year of life. Table II shows the length of follow up in child years, the 
TABLE I-Overall mortality by age at infection with Cryptosporidium spp among 1315 children

\begin{tabular}{|c|c|c|c|c|c|c|c|c|}
\hline \multirow[b]{3}{*}{$\begin{array}{l}\text { Age } \\
\text { (months) }\end{array}$} & \multicolumn{8}{|c|}{ Age at infection } \\
\hline & \multicolumn{3}{|c|}{$1-11$ months } & \multicolumn{3}{|c|}{$12-35$ months } & \multicolumn{2}{|c|}{ Not infected } \\
\hline & $\begin{array}{l}\text { Length of } \\
\text { follow up } \\
\text { (child years) }\end{array}$ & $\begin{array}{c}\text { No (\%) } \\
\text { of deaths }\end{array}$ & $\begin{array}{c}\text { Mortality } \\
\text { ratio }\end{array}$ & $\begin{array}{l}\text { Length of } \\
\text { follow up } \\
\text { (child years) }\end{array}$ & $\begin{array}{c}\text { No (\%) } \\
\text { of deaths }\end{array}$ & $\begin{array}{l}\text { Mortality } \\
\text { ratio }\end{array}$ & $\begin{array}{l}\text { Length of } \\
\text { follow up } \\
\text { (child years) }\end{array}$ & $\begin{array}{l}\text { No of } \\
\text { deaths }\end{array}$ \\
\hline $\begin{array}{r}1-11 \\
12-23 \\
24-47\end{array}$ & $\begin{array}{l}36 \\
54 \\
26\end{array}$ & $\begin{array}{r}6(4) \\
10(2) \\
1(0)\end{array}$ & $\begin{array}{l}2.8^{\star} \\
4.5 t \\
0.9\end{array}$ & $\begin{array}{l}34 \\
60\end{array}$ & $\begin{array}{l}3(0) \\
2(0)\end{array}$ & $\begin{array}{l}2 \cdot 1 \neq \\
0.8\end{array}$ & $\begin{array}{l}442 \\
463 \\
525\end{array}$ & $\begin{array}{l}26 \\
19 \\
21\end{array}$ \\
\hline
\end{tabular}

${ }^{\star} X^{2}=5.64,95 \%$ confidence interval 1.2 to $6.5 ; p=0.018$.

$t x^{2}=18.08,2.3$ to $9 \cdot 1 ; p<0.0001$.

$\mp \chi^{2}=1.54,0.6$ to $6.9 ; p=0.21$

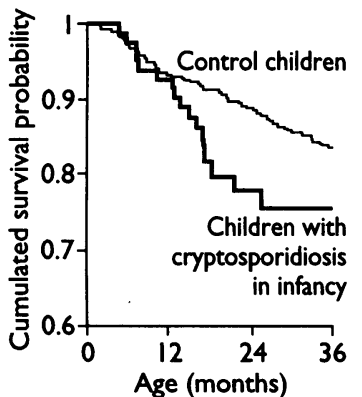

FIG 2-Survival (Kaplan-Meier estimate) of 99 children after cryptosporidium diarrhoea before the age of 1 year compared with survival of 1110 children without cryptosporidiosis. By the age of 3 years 11 children were under observation in the cryptosporidium group and 325 in the control group number of deaths recorded, and the ratio between mortality by age at cryptosporidium infection and by age at follow up. Excess mortality was significant for children who acquired cryptosporidiosis in infancy. After children who may have contracted cryptosporidiosis through contact with someone living in the same house had been excluded the excess mortality was 4.6 in the first year of life $(1.8$ to $11.7, p=0.002)$ and $2 \cdot 8$ in the second year $(1.3$ to $5.7, p=0.006)$.

Figure 2 shows the survival of the 99 children who had cryptosporidiosis before the age of 1 year compared with that of children without cryptosporidiosis. The postneonatal mortality risk at 2 years of age was 214 per 1000 (90 to 338) for children who had cryptosporidiosis in the first year compared with 104 per 1000 (75 to 134) for the control children.

\section{NUTRITIONAL STATUS}

A total of 135 children with a median age of 10 months had their weight measured a median of two months (range one to four months) before their first stool sample was positive for cryptosporidium. They had exactly the same mean weight $(8.2 \mathrm{~kg})$ as the 135 matched controls. Their mean weight for age $\mathrm{z}$ score was -0.74 compared with -0.79 in the control group ( $\mathrm{p}=0 \cdot 60$, paired two tailed $t$ test).

\section{MULTIVARIATE SURVIVAL ANALYSIS}

A survival analysis of all 1315 children with age at cryptosporidiosis, time since infection, and sex included as covariates found no effect of sex. The effect of cryptosporidiosis and time since infection was small and not significant after the age of 1 year. For infections in infancy the excess mortality decreased with time since infection, but the trend was not significant $(p=0 \cdot 12)$. We therefore ignored time since infection and estimated the relative mortality for infection in infancy as $2.9(1.7$ to 4.9$)$ throughout the follow up period. The result is very similar to the stratified analysis presented in table II.

Table III summarises the survival analysis of 555

TABLE III-Proportional hazards survival analysis for 555 children with cryptosporidiosis in Guinea Bissau, West Africa

\begin{tabular}{|c|c|c|c|c|c|}
\hline Covariate (z) & $\begin{array}{l}\text { Length of } \\
\text { follow up } \\
\text { (child years) }\end{array}$ & $\begin{array}{l}\text { No of } \\
\text { deaths }\end{array}$ & $\beta$ & $\begin{array}{c}\text { Relative } \\
\text { mortality } \\
\text { ratio } \\
\left(\mathrm{e}^{\beta}\right)\end{array}$ & $\begin{array}{c}95 \% \\
\begin{array}{c}\text { Confidence } \\
\text { interval }\end{array}\end{array}$ \\
\hline \multicolumn{6}{|c|}{ Cryptosporidiosis in infancy ${ }^{\star}$ : } \\
\hline Before (0) & 808 & 38 & & & \\
\hline After (1) & 139 & 13 & 0.89 & $2 \cdot 4$ & $1 \cdot 2$ to $5 \cdot 1$ \\
\hline \multicolumn{6}{|l|}{ Weaningt: } \\
\hline Breast fed (0) & 441 & 27 & & & \\
\hline Not breast fed (1) & 506 & 24 & 1.05 & 2.9 & 1.2 to 6.7 \\
\hline \multicolumn{6}{|c|}{ Electricity in household: } \\
\hline No $(0)$ & 770 & 47 & & & \\
\hline Yes (1) & 177 & 4 & -1.07 & 0.3 & 0.1 to 1.0 \\
\hline \multicolumn{6}{|l|}{ Pigs in household: } \\
\hline No $(0)$ & 555 & 24 & & & \\
\hline Yes (1) & 392 & 27 & 0.55 & 1.7 & 1.0 to 3.0 \\
\hline \multicolumn{6}{|l|}{ Father's occupation } \\
\hline Unskilled (0) & 420 & 29 & & & \\
\hline Skilled (1) & 527 & 22 & -0.65 & 0.5 & 0.3 to 0.9 \\
\hline
\end{tabular}

$z$ Is the code of the independent variable and $\beta$ is the regression coefficient in the multivariate analysis

Time dependent covariate.

Included as a time dependent covariate: $\mathbf{3 5 4}$ children were weaned during the study, 121 were not breast fed at entry, and 80 were still breast fed at end of follow up. children with complete information on background factors. Even after these factors had been adjusted for the relative mortality ratio was $2 \cdot 4(1 \cdot 2$ to $5 \cdot 1)$.

\section{Discussion}

We have previously shown that cryptosporidium is a common cause of diarrhoea, and in this study it was the only protozoan significantly associated with diarrhoea. ${ }^{5}$ The seasonality of infection, with peak prevalence at the beginning of the rainy season, and the high prevalence among infants and very young children, unusual for an enteric parasite, have been observed previously. ${ }^{9-13}$ However, unlike other studies we found a high acute and delayed excess mortality in otherwise healthy children who had cryptosporidiosis in infancy. This association cannot be assumed to be causal unless possible sources of bias have been considered. We adjusted for breast feeding and possible confounding socioeconomic factors, including family size, domestic animals in house, sanitation, and water supply, and do not believe that our results are significantly flawed by a selection bias.

Cryptosporidiosis is often fatal in patients with AIDS, ${ }^{1}$ but HIV infection is rare in children in Bissau and therefore unlikely to explain the high prevalence and mortality of cryptosporidium infection. ${ }^{14}$ In addition, all children who had cryptosporidium infection in the first year of the study were tested for HIV-2 and had negative results (unpublished data). The children did not have abnormal proportions of subsets of $T$ cells (unpublished results). ${ }^{15}$

The nutritional status before infection of 135 children for whom anthropometric data were available was similar to that of matched controls. We did not measure vitamin A concentrations, but even mild vitamin A deficiency seems to be associated with abnormal $\mathrm{T}$ cell subset proportions. ${ }^{16}$ If vitamin $\mathrm{A}$ deficiency was a significant confounder in explaining the excess mortality the infected children would have been expected to have abnormal $\mathrm{T}$ cell status, or to have been underweight. Of the 205 children who had cryptosporidiosis, only 11 had measles before infection, and they all survived the follow up period. It is thus unlikely that the excess mortality can be explained by malnutrition before infection or postmeasles syndrome; we found no association between cryptosporidiosis and other known enteric pathogens. ${ }^{5}$

Young age at infection seems to be particularly important in explaining the high mortality. Excess mortality was significant only for children who acquired cryptosporidiosis before 1 year of age, and it remained significant during the follow up period. We cannot determine whether the excess mortality reflects failure to thrive after severe persistent diarrhoea or a more specific pathogenesis. The pathophysiological mechanisms and the immunobiology of cryptosporidium induced diarrhoea are still poorly defined. Long term colonisation may occur in immunologically immature infants. We know that the infection results in villous damage and atrophy, mild submucosal inflammation, decreased activity of brush border enzymes, and impairment of the glucose stimulated sodium and water absorption in the jejunum and ileum. ${ }^{17}{ }^{18}$ Infants with impaired mucosal repair can develop a syndrome of chronic diarrhoea and malabsorption. The severity of diarrhoea increased with overgrowth of intestinal microflora, and translocation of bacterial endotoxin across the damaged gut wall may further contribute to the deterioration of the affected child.

Our finding of an increased mortality among infants with cryptosporidiosis after excluding household contacts suggests that some acute cases of cryptosporidiosis may have been missed by the weekly surveillance. In addition, we have reported community 


\section{Clinical implications}

- The protozoan cryptosporidium causes severe diarrhoea in immunodeficient patients

- It is thought to cause only self limiting disease in immunocompetent people

- In this three year community study cryptosporidium was a common cause of persistent diarrhoea and death in otherwise healthy young children

- Prevention or effective treatment of cryptosporidiosis in infancy would reduce mortality in children aged 1-23 months by about $18 \%$

based data with a large number of relatively mild episodes of diarrhoea. A study of infants and young children admitted to hospital with severe diarrhoea would probably show a higher prevalence and mortality.

\section{CONCLUSIONS}

We conclude that cryptosporidiosis in infants in developing countries is not only a common cause of diarrhoea but a cause of excess mortality. Table II shows that in children with cryptosporidiosis in infancy $4 \cdot 3$ deaths $((36 \times 26 / 442)+(54 \times 19 / 463))$ could be expected in children aged 1-23 months. However, 16 deaths were recorded. Eradication of cryptosporidiosis in infancy by prevention and treatment should therefore theoretically reduce the 64 deaths reported in children aged 1-23 months by about $18 \%$ $(11 \cdot 7 / 64)$, assuming that the other factors affecting mortality are equally distributed among the exposed and non-exposed groups. This assumption is supported by the multivariate analysis.

Control of cryptosporidiosis should receive much more attention. Research is needed to improve the understanding of the natural course of the infection and the immunopathogenesis of the associated disease. Despite numerous attempts no consistently effective antiparasitic drug has been found and further research is urgently needed. Cryptosporidiosis can be prevented by measures such as improving domestic and personal hygiene, improving child feeding and lactation practices, and controlling zoonotic reservoirs and water supplies.
We thank Queba Djaná, Domingos Sanca, Mario Rui Lopes, Paulo Ubassé, Jean Gomes Sá, Faustino Umbunque, and Aquinaldo Djaná, for the field work, and Astrid Permin Lene Brink, and Uffe Gansted for their contributions. In particular, we wish to acknowledge Anja Vollmer and Henning Andersen, who died before publication of this study.

This work was supported by the Science and Technology for Development Programme of the European Commission (contract No TS2-0179); the University of Copenhagen, Denmark; the Danish Council for Development Research (grant Nos 104. Dan. 8/341 and 1114); the Danish Medical Research Council (grant Nos 12-6055 and 12-6967); and the Danchurchaid primary health care project in Guinea Bissau.

1 Current WL, Garcia LS. Cryptosporidiosis. Clin Microbiol Rev 1991;4:325-58. 2 Persistent diarrhoea in children in developing countries: memorandum from a WHO meeting. Bull World Health Organ 1988;66:709-17.

3 Sallon S, Deckelbaum RJ, Schmid II, Harlap S, Baras M, Spira DT Cryptosporidium, malnutrition, and chronic diarrhea in children. $A m \mathcal{f} D$ Child 1988;142:312-5.

4 Laxer MA, Alcantara AK, Javato-Laxer M, Menorca DM, Fernando MT, Ranoa CP. Immune response to cryptosporidiosis in Philippine children. Ranoa CP. Immune response to cryp

5 Molbak K Hojlyng N, Ingholt L, da Silva APJ, Jepsen S, Aaby P. An epidemic outbreak of cryptosporidiosis: a prospective community study epidemic outbreak of cryptosporidiosis: a prospective

6 Allen AVH, Ridley DS. Further observations on the formol-ether concentration technique for faecal parasites. $\Im$ Clin Pathol 1970;23:545-6.

7 Henriksen SAa, Pohlenz JFL. Staining of cryptosporidia by a modified ZiehlNeelsen technique. Acta Vet Scand 1981;22:594-6.

8 Kleinbaum DG, Kupper LI, Morgenstern H. Epidemiologic research. New York: Van Nostrand Reinhold, 1982.

9 Mata L, Bolanos H, Pizarro D, Vives M. Cryptosporidiosis in children from some highland Costa Rican rural and urban areas. Am f Trop Med Hyg 1984;33:24-9.

10 Cross JH, Alcantara A, Alquiza L, Zaraspe G, Ranoa C. Cryptosporidiosis in Philippine children. Southeast Asian $\mathcal{F}$ Trop Med Public Health 1985;16: 257-60.

11 Højlyng N, Molbak K, Jepsen S. Cryptosporidium spp, a frequent cause of diantoea in Liberian children.7 Clin Microbiol 1986;23:1109-13.

12 Pal S, Bhattacharya SK, Das P, Chaudhuri P, Dutta P, De SP, et al. Occurrence and significance of cryptosporidium infection in Calcutta. Trans R Soc Trop Med Hyg 1989; 83:520-1.

13 Fripp PJ, Bothma MT, Crewe-Brown HH. Four years of cryptosporidiosis a GaRankuwa Hospital. Y Infect 1991;23:93-100.

14 Poulsen A-G, Kvinesdal B, Aaby P, Melbak K, Frederiksen K, Dias F, et al Prevalence and mortality from human immunodeficiency virus type 2 in Bissau, West Africa. Lancet 1989;i:827-31.

15 Lisse IM, Whittle H, Aaby P, Normark M, Gyhrs A, Ryder L. Labelling of T cell subsets under field conditions in tropical countries. $f$ Immunol Method 1990;129:49-53.

16 Semba RD, Muhilal, Ward BJ, Griffin DE, Scott AL, Natadisastra G, et al Abnormal $T$ cell subset proportions in vitamin-A-deficient children. Lancet Abnormal T cell

17 Su S-X, Fang G-D, Fayer R, Guerrant RL. Cryptosporidiosis: pathogenesis and immunology. Parasitology Today 1992;8:24-7.

18 Argenio RA, Liagos JA, Levy MI Meuten DJ, Lecce JG, Powell DW. Argenzio RA, Liagos JA, Levy ML, Meuten DJ, Lecce JG, Powell DW.
Villous atrophy, crypt hyperplasia, cellular infiltration, and impaired glucose-Na absorption in enteric cryptosporidiosis of pigs. Gastroenterolog 1990;98:1129-40

(Accepred 3 Fune 1993)

\title{
Urinary microalbumin excretion in early pregnancy and gestational age at delivery
}

\author{
Ivan J Perry, Peter Gosling, K Sanghera, \\ David Churchill, D M Luesley, D G Beevers
}

Urinary microalbumin excretion in pregnancy may be an early marker for pre-eclampsia, although findings from small clinical studies are inconsistent. ${ }^{12}$ The relation between microalbumin excretion and other end points in pregnancy, such as gestational age at delivery, has not been considered. In a study that was primarily concerned with early markers for preeclampsia we examined the relation between microalbumin excretion in early pregnancy and gestational age at delivery.

Correspondence to:

Dr Perry.

$B M \Im$ 1993;307:420-1
Subjects, methods, and results

We studied clinical and laboratory markers of preeclampsia in 692 healthy, nulliparous pregnant women referred for antenatal care before the 31 st week of gestation. Data on urinary microalbumin excretion at the first antenatal visit (median (interquartile range) gestation 16 (12-17) weeks) were available for 241 women. Urine samples (which were additional to samples obtained routinely) were not available for all women because of limited staff at some clinics and storage problems. The ethnic distribution of the 241 women reflected that the larger cohort of 692 women and that of nulliparous women referred to our unit. After the exclusion of women with essential hypertension, twin births, renal disease, and missing data on gestational age, 233 women were available for analysis.

Urinary albumin excretion rates were estimated from the albumin:creatinine ratio in random, "spot" urine samples taken after the women had sat for about one hour. ${ }^{3}$ The urine specimens were stored in glass containers, frozen at $-20^{\circ} \mathrm{C}$ on the day of sampling, and assayed within four to eight weeks. All specimens were submitted for analysis unless they were blood stained or greatly contaminated. The specimens were assayed by using a double antibody radioimmunoassay (Diagnostic Products Corporation, Wallingford, Oxfordshire).

Gestational age was estimated from the date of last 